\title{
VICTORIA OCAMPO: UN DUELO CON LA SOMBRA DEL VIAJERO1.
}

\author{
DRA. MARÍA ROSA LOJO \\ CONICET-UBA-Universidad del Salvador
}

\section{IDOLATRÍA Y DECEPCIÓN.}

En 1951, Victoria Ocampo (1890-1979) da a la imprenta un libro de su autoría, tan breve como extraordinariamente polémico. Se trata de El viajero y una de sus sombras. Si su título evoca el conocido ensayo de Federico Nietzsche (El viajero y su sombra), se refiere en este caso a otro filósofo de lengua alemana menos célebre: el conde Hermann von Keyserling (1880-1946), cuya relación con Victoria había comenzado veinticuatro años atrás. La "sombra" lo es en más de un sentido. Ante todo, porque Keyserling ya ha muerto, no sin antes dejar un libro de memorias: Viaje a través del tiempo, cuyo último capítulo está dedicado a Victoria Ocampo. Contra esa sombra desdoblada --el sujeto autobiográfico que construye Keyserling y el Keyserling de su propio recuerdo²-- se debatirá Victoria en un duelo verbal que no hará sino clausurar un prolongado y tácito duelo interior.

\footnotetext{
1 Trabajo leído en las VII Jornadas de Historia de las Mujeres y II Congreso Iberoamericano de Estudios de Género, Salta, Argentina, 24 -26 de julio de 2003.

2 El título completo de la obra, a manera de réplica desde "el vamos", es El viajero y una de sus sombras. Keyserling en mis memorias.
} 
Hacia 1927 Victoria Ocampo había dado los primeros pasos de una carrera intelectual. Además de artículos diversos en el diario La Nación, había publicado dos obras en la editorial de Ortega y Gasset: una pieza teatral ( $\mathrm{La}$ laguna de los nenúfares) y un ensayo (De Francesca a Beatrice). Pero en ese momento de su vida profesaba más vacilaciones que certezas y se consideraba, ante todo, una discípula. Se había deslumbrado en 1916 con el talento de Ortega (no con sus seducciones masculinas, como presumiblemente lo hubiera deseado el filósofo); había sido en 1924 la devota anfitriona del Premio Nóbel Rabindranath Tagore. No contenta con la mera letra de los libros, juzgaba que a la sabiduría -arte y ciencia de la vida - había que ir a buscarla en sus fuentes: esto es, en el contacto con los maestros que habían escrito los libros, y estaban por ello capacitados, según creía, para transmitir ese conocimiento del "buen vivir". Su reacción ante la obra de Keyserling fue inmediata y apasionada 3 , y no vaciló en manifestársela por correo: "The travel diary y The world in the making me absorben de tan tiránica manera que me será difícil callar lo que significan para mí. Para mi propia satisfacción le diré al menos que el descubrimiento de sus libros me ha procurado una felicidad de una calidad y una intensidad tales que he pasado varios días sin resolverme a desprenderme de ellos, ni siquiera materialmente. Cuando me resultaba imposible leerlos, su presencia material me era siempre necesaria. [...] Los llevaba conmigo a la mesa. Hacía caminatas con un volumen debajo del brazo." 4 A esta primera comunicación sucederán otras, de un tono aún más fervoroso, entretejidas con metáforas de fuerte brillo sensual que se trasladan, del elogio de la obra, a la fusión con el idealizado "fantasma" que se ha convertido en su corresponsal: “iSol de sus cartas! Déjeme adormecer en ellas, detenerme en ellas. Y después floreceré por ellas." "Me parece que estoy tan plena de lo que es usted, que el menor movimiento me llevaría a despedir algún precioso aroma" 5 La discípula llega a atribuir a ese vínculo virtual el carácter de condición necesaria para su mera supervivencia: "Cuando llegan sus cartas, siempre me parece que un instante antes me ahogaba y lo comprendo mejor por el alivio inmediato que este oxígeno me proporciona. Lo leo con los pulmones."6 Si Keyserling, fundador de la Escuela de la Sabiduría, hubiera sido un exégeta más sutil y menos narcisista, hubiese entendido, acaso, que no se trataba de una adoración dirigida a su persona

\footnotetext{
3 Esta relación de verdadera idolatría intelectual, motivó las irónicas palabras de una carta de Ortega, cuando vuelve a la Argentina en 1928 y encuentra a Victoria "colonizada por ilusiones de Alemania [Keyserling] y recuerdos hindúes [Tagore]" (carta inédita). Tanto Ortega como la educadora española María de Maeztu (amiga de V.O. desde 1926) la habían advertido acerca de la personalidad del Keyserling "real".

4 Autobiografía IV, 137-138.

${ }_{5}^{5}$ Ambas frases corresponden al 10 de noviembre de 1927, Autobiografía IV, p. 140.

${ }^{6}$ Autobiografía IV, 144.
} 
Victoria Ocampo: un duelo con la sombra del viajero.

(menos aún a su todavía ignota persona empírica) sino de gratitud y gozo por el descubrimiento de sí misma que Victoria Ocampo parecía haber logrado a través de la iluminadora escritura de su interlocutor. Ella lo señala, por cierto, con claridad: "No conozco a Keyserling. Únicamente conozco a mi Keyserling. [...] No se deje desanimar por ese mi. Mi significa simplemente la suma total de todo [...] eso que, en mi ser, lleva su nombre, aunque siendo, por esencia, yo misma."7

Pero ni el conde ni Victoria estaban dispuestos a comportarse como buenos críticos, capaces de trascender su propio ensueño para escuchar todas las resonancias de la voz del otro. Las consecuencias de la "mala lectura" se harían ver pronto, en el versallesco Hôtel des Réservoirs donde ambos habían quedado en encontrarse, por pedido de Victoria, en enero de 1929. No le faltaban a ésta algunos motivos para alentar prevenciones: el conde, cuya estadía y gastos corrían por cuenta de su invitadora, le había enviado, por escrito, una lista germánicamente ordenada de dispares exigencias, entre las que figuraban, por ejemplo, una cena con ostras, champagne, y argentinos y argentinas selectos y vestidos de etiqueta, así como la prohibición de que su "mecenas" contrajese cualquier compromiso fuera de los cotidianos coloquios filosóficos que sostendría con él. La ilusión, sin embargo, era más fuerte, y duró hasta el "día transcendental" en que se enfrentó con Keyserling cuerpo a cuerpo. El sutil viajero filosófico que se había trasladado a los extremos del mundo para encontrar la síntesis posible de Oriente y Occidente le pareció entonces por completo incompatible con el gigante de ojitos rasgados $\mathrm{y}$ temperamento de guerrero mongol $^{8}$ que devoraba cenas pantagruélicas, consumía litros de champagne y además exigía realizar, perentoriamente, otra síntesis cósmica: la de lo Femenino y lo Masculino, la de lo Telúrico y lo Espiritual en las encarnaciones físicas de su propia persona y la de su admiradora sureña. Mientras el conde hablaba y comía, Victoria callaba. Estaba "demasiado entrampada en la admiración que le había dedicado a lo largo de dos años" 9 o en la costumbre de "generaciones y generaciones de seres que sólo practicaron el silencio"10. Por otro lado, comprometida ya a realizar los trámites para la inminente gira argentina del filósofo, no se atrevía a la repulsa directa, única opción restante, ya que "Keyserling permanecía sordo y ciego a mis insinuaciones y a mis espantadas de potro arisco."11

\footnotetext{
${ }^{7}$ Autobiografía IV, 141.

8 Keyserling, nacido en el Báltico (Könno, Livonia) pertenecía a la minoría alemana dominante, pero tenía también sangre eslava y mongol.

9 , Autobiografía $V, 26$.

${ }_{10}$ El viajero..., 44 . Victoria cita aquí una carta que ella misma le había escrito a Keyserling meses antes.

11 El viajero..., 63.
} 
La repulsa "a coces" se hará imprescindible en Buenos Aires, ante la inquebrantable insistencia del conde, que no sólo se hace famoso por sus charlas, sino por su desfachatada conducta en banquetes y recepciones ${ }^{12}$. Por otra parte, la decepción de éste es abrumadora: "Nada quedaba ya de aquella donna umile, de aquella fervente admiratrice, de aquel ser para quien mi espíritu había significado todo."13; "la brusca evasión de Victoria de mi poesía constituía la tercera gran catástrofe del alma que hasta entonces se había abatido sobre mí"14

\section{UNA MUJER TELÚRICA Y SERPENTINA.}

Keyserling, sin embargo, no estaba del todo desvalido frente a su perplejidad y su despecho. Contaba con un arma de vasto alcance que utilizaría oportunamente en Europa después de la ruptura de relaciones con su antigua "fan". Si Sarmiento diseñó la trayectoria de su Facundo como un tiro por elevación destinado a Rosas, no sería exagerado afirmar que Keyserling escribió las Meditaciones Suramericanas (él lo reconocerá en sus memorias) inspirado por (y también contra) Victoria Ocampo ${ }^{15}$. Victoria y Sudamérica, mujer y tierra, identificadas, conformarán un solo bloque reacio a la dirección del Espíritu Occidental.

El filósofo -siguiendo a su modo las reflexiones de Hegel sobre América - define a Sudamérica (y a la Argentina en particular) como un "mundo arcaico", "a medias creado", "materia prima o un mero esbozo" (40), reino de los reptiles correspondiente al "Tercer Día de la Creación", "mundo ciego y obtuso", "abisal" (29), "en constante fermentación" (28) donde el hombre contempla "involuntariamente, cara a cara, la Magna Mater" (31). Las imágenes femeninas tienen un peso poderoso en la definición de esta terra incognita, ante todo porque los valores que la determinan: --la delicadeza, la "gana", el orden emocional - son, para Keyserling, esencialmente propios de la femineidad mientras que lo masculino está gobernado por el intelecto racional, y sobre todo, por el Espíritu. El segundo capítulo del libro se abre, justamente,

\footnotetext{
12 Conducta que no sólo registró Victoria Ocampo, sino -más o menos en los mismos términos otros escritores que no habían tenido con el conde ningún conflicto personal, como María Rosa Oliver $(1969,255)$ y Eduardo Mallea $\left(1994-1^{a}\right.$ ed $\left.1937-133\right)$. Cfr. V.Ocampo, Autobiografía VI..

${ }^{13}$ Conde Hermann von Keyserling. (Viaje a través del tiempo, 1951, 471).

14 Viaje..., 471.

${ }^{15}$ Cuando se refiere en Viaje... a las Meditaciones Suramericanas, señala que escribió el libro "en la órbita de la mujer más fantástica que encontré en mi vida" (461), y que "Mi sentimiento por Victoria se transfirió a todo su continente y a sus moradores..." (476). "Así la sensación de haber sido traicionado me hizo transfigurar a Victoria en diablesa o india que a mansalva me disparaba flechas envenenadas." (475).
} 
Victoria Ocampo: un duelo con la sombra del viajero.

con la visión de una "enigmática criatura", ser híbrido entre lo femenino y lo animal: "cuerpo indefinible, mujer, serpiente, amiba y pulpo al mismo tiempo, manos y pies desarrollándose como tentáculos, escurridizos como pseudópodos, y una angosta cabecita femenina", que lanza gritos plañideros sobre el mar desierto. Esta "nueva esfinge",muy poco sabia, representa la "conciencia de la debilidad, el hambre y el miedo primordiales" (46)

Dentro de la tipología keyserlinguiana de los sexos, roles y capacidades se dividen por género, como disposiciones ontológicas, completamente "naturalizadas". Aunque su concepción irracionalista y vitalista considera al "orden emocional" (femenino) enraizado en la tierra, como imprescindible eje de lo humano, la función superior del Espíritu, la aptitud para trascender, para "salir de sí", construir libertad, producir nuevas realidades y otorgar sentido, se atribuye al Logos masculino y creador ${ }^{16}$. En definitiva, dice Keyserling tranquilamente, la Historia la hacen los varones. "[...] sólo historia de los hombres puede haber, pues sólo la modalidad de vida masculina exige dinamismo, progreso y ascensión" (311) La mujer, "parte telúrica de la humanidad" (390) se definiría en cambio -en su estado puro o prístino- por los siguientes rasgos: el "miedo original", que la lleva a buscar la seguridad (la propiedad) para ella y su progenie, por sobre toda otra cosa; la predisposición a la mentira y el fingimiento (necesarios para lograr sus fines); la carencia de ética (plano espiritual, mientras que todo en la mujer es "natural"); el sentido práctico, la incapacidad imaginativa, el realismo; la "ceguera" ante las entidades espirituales, la obediencia irrestricta a la "gana", al impulso; la pasividad, la inercia que la lleva a eludir decisiones y responsabilidades, a tal punto que prefiere ser violada y conquistada por la fuerza; el deseo de la esclavización y el sufrimiento; el culto al héroe; la necesidad -al carecer de autonomía espiritualde recibir su ley de una fuente externa (el mandato del varón); la sensibilidad, la belleza y la riqueza emocional - rubros éstos en los que supera al hombre--.

Esta mujer primordial, que no toma en serio los fines más altos del varón, desviados, por ser fines espirituales, de la Naturaleza, es sin embargo su gran inspiradora, su Musa, porque libera para la creación todas las energías vitales masculinas. En cambio la "mujer intelectualizada" no puede ser para el hombre Musa ni Sibila. No hay peor disfraz que el de la "mujer telúrica"

16 También Ortega y Gasset se manejaba con este tipo de parámetros dualistas en cuanto a la tipología de los géneros sexuales. Como Keyserling, atribuía a las mujeres un papel civilizador de los varones a través de la "educación sentimental" y la cortesía (Provenza) y consideraba que el mundo occidental contemporáneo se "masculinizaba" lamentablemente. Jung, con quien Keyserling mantuvo tanto coincidencias como disidencias, también utilizaba un esquema de contraposiciones masculino y femenino, pero consideraba, más acentuadamente que Keyserling, y con más finos matices, que estas contraposiciones existìan en todos los seres humanos, varones y mujeres. 
cuando se intelectualiza, contrariando así su destino y naturaleza. "En el último rincón del mundo" -dice Keyserling-ha encontrado también "los últimos ejemplares de las femmes savantes de Molière, patéticas en su prístina autenticidad, mujeres para las cuales el espíritu y la actividad espiritual eran aún algo anormal y que, por cultivar tal excentricidad, habían perdido totalmente el gusto y el tacto, la intuición femenina y el sentido de la realidad" (111) Tales "mujeres sabias", afirma en otra parte, son egocéntricas, autoritarias, aún más ávidas de poderío que los mismos caudillos. Su extremado sentimiento de propiedad las hace sentirse siempre en su derecho, dueñas de la razón como pueden ser las dueñas de un vestido. Su "yo" hipertrofiado les deforma la personalidad como una patología; les aguarda un final propio de la "malvada" del teleteatro o culebrón: terminarán "desgraciadas y solas, abandonadas por hijos y amantes". Sólo les queda consolarse ocultando su miseria interior con su poder o su riqueza. (291-292). Cualquier parecido con Victoria no era mera coincidencia. ${ }^{17}$

En Viaje a través del tiempo, Keyserling aborda ya sin rodeos ni ambages el tema Ocampo. La describe como el "más elemental y telúrico de los temperamentos" (462), "mujer prístina" que padecía un desdoblamiento cuerpo/espíritu (461-462) y "deliberadamente vivía para intereses intelectuales y artísticos" con la aspiración de liberarse de su "destino de gana", del "estado de tristeza de la criatura" (467). Inconsciente de su fascinación primigenia, "carecía también de toda maldad"; "daba la impresión de una serpiente apacible y gigante que por pura distracción, estrujaba en el abrazo" (466). Su narrativa de la relación epistolar, del encuentro y de la decepción mutua será duramente comentada y rectificada por la refutación de Ocampo.

\section{EL TELURISMO DEL VIAJERO.}

Victoria despliega, tanto en El viajero... como en la Autobiografía, una rica batería de armas lógicas, psicológicas, retóricas: 1) Argumentos ad hominem, basados en la conducta del conde y en las contradicciones de ésta con su proclamado pensamiento. 2) Argumentos ad hominem que apuntan a la personalidad del filósofo, a sus deseos y temores, a su historia, y propugnan desde ella-- una "teoría de la proyección" para explicar sus interpretaciones 3)

17 Aunque Keyserling evita nombrar directamente a Victoria (salvo cuando se refiere a su libro sobre Dante para describir los efectos de la "gana" ciega, basándose en su descripción de Paolo y Francesca), existen en las Meditaciones... claras referencias a la vida personal de Ocampo, que la autobiografía de ésta convalida. Por ejemplo, cuando menciona como ejemplo de la "mudez" abisal sudamericana, el caso de una mujer que vivió diez años bajo el mismo techo con un marido al que no amaba sin dirigirle la palabra $(1933,182)$. 
Victoria Ocampo: un duelo con la sombra del viajero.

Argumentos lógicos que exhiben la falta de fundamento o las contradicciones internas de los razonamientos de Keyserling 4) Argumentos lógico-empíricos que, basados en el conocimiento de la génesis de las Meditaciones, muestran su endeble punto de partida y metodología. 5) Apelación paródica a personajes históricos y mitológicos (Orfeo, Pentesilea, Cibeles, Tamerlán, Gengis Khan, Júpiter y Leda, etc.) para explicar, en burlesco paralelo identificatorio, las relaciones Ocampo/Keyserling. 6) Hábil empleo de metáforas y comparaciones cotidianas y terrenales, que "bajan" tanto a Keyserling como a la problemática discutida, de los altos niveles del Espíritu donde éste pretendía colocarla y colocarse ${ }^{18}$. Veamos algunos usos:

¿Quiénes son realmente "telúricos" y "primordiales"?, se pregunta Victoria, ¿lo son las mujeres, o los varones las califican así porque ante ellas despiertan sus instintos más primarios? ¿Por qué, en una mujer, la admiración intelectual debe ser inexorablemente acompañada por la entrega física al sujeto admirado, so pena de ser acusada de un patológico desdoblamiento cuerpo/espíritu? Si bien reconoce que el lenguaje de sus cartas pudo haber conducido a equívocos, también señala que el propio Keyserling veneró con los mismos visos de exaltación extrema al ensayista inglés Houston Chamberlain sin que por ello se supusiese en él una pasión homosexual. ¿Es que el derecho a sostener relaciones puramente intelectuales está reservado sólo a los varones? ¿Existe algún fundamento razonable para suponer que el falo es más espiritual que un ovario o un útero? ¿O se trata, antes bien, de un "error consolidado por la razón y el interés del más fuerte?" (40) La Autobiografía (Tomos IV y V) reitera y prolonga estas reflexiones. Ocampo desestima la definición de la mujer en función exclusiva del deseo masculino que practica Keyserling, dividiendo al "segundo sexo" en "clases de mujeres" según su funcionalidad para el varón (la prostituta, la esposa y madre de familia, la Musa o Gran Dama) ${ }^{19}$.

En cuanto a la realidad sudamericana, Keyserling, que se jacta de no atenerse a los hechos, padece -afirma Ocampo-- de "elefantiasis interpretativa". También aquí cabe el argumento de la proyección. El conde, que reacciona "a toda impresión desagradable como un brasileño o un argentino cualquiera" (El viajero, 66) es un hombre temperamental y primitivo, violento y susceptible; cuando atribuye estos defectos a los sudamericanos, en realidad no hace sino

18 Así, el filósofo de lo trascendental, es capaz de incurrir en ataques de cólera por un puré de papas: “la relación con su persona cotidiana, con sus reacciones al Espíritu con mayúscula y al puré de papas con minúscula...me habían instruido sobre los límites de mi aguante" (El viajero..., 65)

19 Autobiografía $V, 16-17$. Se refiere particularmente a otra obra de Keyserling, una de las primeras que ella leyó: Diario de viaje de un filósofo (I, 188-193). También en esta obra hombre y mujer se definen por oposiciones, aunque se acentúan menos los aspectos ctnónicos y siniestros de lo femenino. 
mirarse en el espejo20; por lo demás ha resultado mucho más torpe. Un sudamericano cualquiera no se hubiese engañado nunca en cuanto a los sentimientos de rechazo de Victoria ${ }^{21}$. Tanto ella como Sudamérica -afirma-fueron para él como las manchas del Test de Roscharch donde se ve tan sólo lo que uno mismo es, y lo que se desea ver. Por lo demás, cualquier anécdota trivial y parcial (como la que funda su "teoría de la gana") parece dar pie a su "fantasía desbocada": "como las personas de gran memoria musical pero demasiado perezosas para aprender a leer a primera vista la música, analizaba de oído los países." (74-75)

Ocampo se niega a aceptar la dicotomía espiritual/telúrico, primitivo/civilizado, natural/cultural, noble/plebeyo, señor/vasallo, que domina la visión keyserlinguiana de Sudamérica, y de la "naturaleza femenina", porque carece, a su juicio, de fundamento y porque está impregnada (y falseada) por las pasiones del filósofo, que no era "ni santo, ni sabio". Como el mismo Keyseling lo señala en Viaje a través del tiempo, Sudamérica ha despertado en él conflictos profundos: sobre todo, el conflicto con su propia madre, Johanna Pilar von Pilchau, que, al enviudar del Conde Keyserling, dispuso a su gusto de su propia vida, se casó con el preceptor de sus hijos (ruso, periférico, plebeyo), y participó activamente en la lucha por los derechos de las mujeres ${ }^{22}$ y de las clases postergadas de la sociedad. La "infidelidad", la "desobediencia" de su madre cuando "desciende" a la clase inferior, y quiebra el mandato familiar de clase y de sangre, se habría unido a la resistencia de Victoria a plegarse a sus deseos. Ambas habrían confluido en una imagen femenino-materna de rasgos demoníacos que estalla (dentro del conde) no bien éste pone pie en Sudamérica.

Por fin, así como se rehusara -años atrás - a ser capturada por la mucho más halagadora simbología orteguiana (la "Gioconda de las Pampas"), Victoria sigue refractaria (en nombre de ella misma y de su género) a ser transformada en mito: "la verdad de mi persona, como ser humano, no era respetada, [....] como el ladrillo para el albañil que con su llama le aplica la argamasa, sin pedirle permiso. Pero el caso es que este ladrillo, como el junco de Pascal, es un ladrillo pensante." (106) La relación entre hombres y mujeres -había dicho en La mujer y su expresión - ha sido a lo largo de la Historia humana un incesante monólogo masculino que las mujeres no se atreven a interrumpir (y si lo

$20 \mathrm{La}$ "teoría de la proyección" tiene un exponente temprano, anterior a las confesiones de Keyserling y a la interpretación de Ocampo en Eduardo Mallea (1994 -1º ed 1937--, 136).

21 “Un latino, de cualquier día de la creación, no se habría equivocado” (El viajero..., 64)

22 "Comenzó una vida totalmente nueva, en la cual, una vez que hubo echado nuevas raíces, hizo, sobre todo, bien. Se preocupó apasionadamente de todo lo relacionado con la emancipación de la mujer y con la justicia social, y lo hizo como demócrata fanática y como representante de la fe en la igualdad niveladora, compensando así la conciencia de haber sido infiel a la tradición..." (1949, 469). 
Victoria Ocampo: un duelo con la sombra del viajero.

interrumpen con alguna respuesta, no logran sacar al varón de su ensimismamiento). Fiel a esa tenaz costumbre, Keyserling no se ha escuchado más que a sí mismo²3.

Por su parte, Ocampo no deja de reconocer su sobreabundante "hero worship", su "pecado de idolatría", que no se ha extendido sólo a Keyserling24. Por otro lado, admite que el conde ha cumplido su papel de "incitador" en varios sentidos. A partir de su tesis de la "fecundidad de lo insuficiente" Victoria ha canalizado su sentimiento de carencia en una aventura intelectual cada vez más vasta, y ha encontrado la "misión" que trasciende lo individual 25. $\mathrm{Su}$ desencanto personal ha sido, además, el factor desencadenante que la conduce a hacerse cargo de sus propias aspiraciones de creación y trascendencia26. "Un año después de este ajuste de cuentas" -dice-- decide fundar Sur, asqueada de la "profesión" de "secretaria-dueña-ama de casa" (El viajero..., 70). Si el choque con Keyserling la lleva a tomar brusca conciencia de los sofismas que "naturalizan" la cuestión de género (y las culturas periféricas y hegemónicas) en ontologías metafísicas, no obstante, algo de las ideas del filósofo (al que nunca dejó de considerar talentoso) queda en su propia visión de Sudamérica y su lenguaje, particularmente en el ensayo Supremacía del alma y de la sangre27. Allí señala justamente que el error del viajero "determina en nosotros un retroceso instintivo hacia nuestra verdad" (17) "Por otra parte" concede - "no todo es error, ni mucho menos, en esos ensayos." (18). No sería error, por lo menos, la atención que Keyserling ha prestado a los "problemas del orden emocional" (40) en Sudamérica, donde se siente -dice Ocampo-- como en ningún otro lugar, el peso del "alma y de la sangre", el espesor carnal de la vida, aunque el filósofo los haya visto de manera insuficiente, como a través de un telescopio. Los poetas sudamericanos (así Ricardo Güiraldes, al que cita) utilizan, por lo tanto, un lenguaje adecuado a esa experiencia de alta densidad. El mismo lenguaje, acaso, que, empleado en sus cartas a Keyserling, ha

\footnotetext{
23 El viajero..., 112.

24 "Me he preguntado a menudo si mi 'mala ventura' keyserlinguiana no es una manera de expiación por la 'casi monstruosa y casi continua superabundancia de emoción religiosa gastada en todo objeto profano" (Charles du Bos) que es mi lote en esta vida." (El viajero..., 93). Cfr. también 68-69.

25 Da cuenta de esa búsqueda, orientada por la lectura de Keyserling, especialmente en su Autobiografía, IV, 124 y ss: "Este deseo de ir más allá de lo individual..comenzaba a obsesionarme cada vez más. Yo no concebía otra salvación." (125)

26 Así lo señala con acierto Doris Meyer. "It forced her to recognize her tendency to heroworship for what it was: a projection of her own creative aspirations". $(1979,90)$ (ver 70-91).

27 Buenos Aires, Sur, 1935.
} 
conducido a la "mala lectura" del europeo, a la "confusión de los sentimientos". ${ }^{28}$

\section{UN CUARTO PROPIO/ UN SABER PROPIO.}

El debate con la sombra del viajero (1951) se prolonga en otro debate sostenido en Sur (1952) con un escritor argentino (Ernesto Sábato) que no le debe poco al pensamiento keyserlinguiano, aunque no lo explicite. En efecto, Sábato apela también a dicotomías sexistas, aunque, como Keyserling, asegure que las mujeres (telúricas y emocionales) ${ }^{29}$ constituyen la "humanidad", "no el hombre, que solo no significa nada" (45). No obstante, el dinamismo, el progreso, la Historia, siguen perteneciendo al varón, capaz de "trascender la pura subjetividad, a la búsqueda de otros mundos", mientras que la mujer se abroquela en la pasividad y la inmanencia de la gestación, en el pequeño ámbito doméstico. El ensayo de Sábato genera un debate con Victoria en el que ésta utiliza los mismos procedimientos elegidos para desarmar al filósofo báltico: marcar la falta de fundamentos objetivos en la descripción esencialista de los géneros, señalar las contradicciones internas, y mostrar, con irónicas metáforas, símiles y alusiones muy terrenales, el carácter humano, demasiado humano del intelectual varón ${ }^{30}$.

Por fin, el triple número de Sur dedicado a "La Mujer" (1971) recoge y resume la posición de Victoria Ocampo ante la cuestión femenina, así como los trabajos de un vario y vasto elenco de colaboradores (varones y mujeres). Dos íconos contrapuestos y complementarios (una aborigen guaraní -figura de Águeda, antepasada de Ocampo- y una intelectual europea: Virginia Woolf ${ }^{31}$ ) abren este número consagrado a las mujeres, no como minoría, sino como la

\footnotetext{
28 Tal argumento proporciona Ketaki Kushari Dyson (basándose en este ensayo de Ocampo) para comprender los equívocos que también se producen en su relación con Tagore, a raíz de las cartas exuberantes y apasionadas que ella le envía: "She had no other language with which to communicate with Tagore except her primitive soul-and-blood language, the language of passion, tingled with spiritual thirst. Tagore and Elmhirst [el secretario del poeta] decoded it from their point of view as the language of love." $(1988,249)$

29 "la mujer permanece habitualmente en ese magma fundamental de la carne y de la raza, en ese caótico subsuelo de la existencia,..." (Sur, 209-210, 31)

30 Por ejemplo: "Reconozco que no es culpa suya. Las mujeres educan al hombre, y con ellas debe uno tomárselas cuando el hombre (ensayista o lo que fuere) sigue conduciéndose como un chicuelo, incapaz de soportar que se lo contradiga sin manifestar su mala crianza." (Sur, 213-214, 162).

31 Virginia Woolf, junto a Emily Brontë, es una referente femenina fundamental de la etapa de madurez de Victoria Ocampo. Le dedicó varios trabajos, incluso un libro breve: Virginia Woolf en su diario. Publicó en la editorial Sur la novela Orlando, traducida por Borges. Woolf, para Ocampo, había logrado, sin crispación ni afectación, escribir naturalmente como mujer.
} 
Victoria Ocampo: un duelo con la sombra del viajero.

mitad del género humano. Este número es para Victoria una culminación; significa saldar la antigua deuda con una enorme inquietud personal neutralizada por el desinterés masculino: "Hace años que deseaba dedicarle un número de SUR a la mujer, a sus derechos y a sus responsabilidades. Desde que apareció la revista esa idea me rondaba. Pero no era un tema 'literario' y poco interesaba a los hombres que conmigo compartían las tareas revisteriles. Eran mayoría". (4) "A mí también me libera y aliviana la publicación de este número que desde hace años siento ansias de sacarme de encima literalmente." (4-5).

Para ese momento, Victoria Ocampo ya no se limita a escuchar el "saber de los viajeros", en la actitud (que ella misma describió con humor ácido en el artículo "Quiromancia de la Pampa") de quien tiende una mano al adivino para que devele los secretos de una elusiva identidad y de un futuro misterioso. Ha ganado el combate con la sombra de Keyserling. Viajera de varios mundos, ya sabe -porque lo ha caminado - el rumbo decisivo de su vida. La antes reverente y silenciosa anfitriona de hombres célebres ha construido un prestigioso espacio cultural (ya canónico) compartido -en un plano igualitario - por varones y por mujeres, por europeos, americanos del Norte, y sudamericanos. En este espacio, ni las mujeres, ni los sudamericanos/as renunciarán a sus palabras propias en obsequio a un Logos pretendidamente modélico y universal.

Como lo había afirmado en La mujer y su expresión (1936), no se trata de que la mujer ocupe el puesto del varón, sino de que ocupe por entero el suyo, para ser, ante todo frente a sí misma, lo que debiera ser. La literatura (y la cultura toda) se beneficiará y completará con el rescate (hacia el pasado) y la edificación (hacia el futuro) de una tradición femenina. Las mujeres ya no serán la incomprensible "diferencia", lo marginal, frente al indiscutible patrón de medida. Desde una percepción intelectual no menos valiosa, hablarán, por fin, de sí mismas, y también de los "otros", los varones, tal como los varones han hablado de ellas: "Y es a la mujer a quien le toca no sólo descubrir este continente inexplorado que ella representa, sino hablar del hombre, a su vez, en calidad de testigo sospechoso. Si lo consigue, la literatura mundial se enriquecerá incalculablemente, y no me cabe duda de que lo conseguirá." (p. 23). 


\section{BIBLIOGRAFÍA MENCIONADA}

Keyserling, Conde Hermann von. Diario de viaje de un filósofo. I y II. Madrid: Espasa-Calpe, 1928.

Meditaciones Suramericanas. Madrid: Espasa-

Calpe, 1933. Traducción de Luis López Ballesteros y de Torre.

Viaje a través del tiempo. I. Origen y desarrollo.

Buenos Aires: Sudamericana, 1949. Traducción de J. Rovira Armengol.

Viaje a través del tiempo. II. La aventura del alma. Buenos Aires: Sudamericana, 1951. Traducción de J. Rovira Armengol.

Kushari Dyson, Ketaki. In Your Blossoming Flower Garden, Rabindranath Tagore and Victoria Ocampo. Delhi: Sahitya Akademi, 1988.

Mallea, Eduardo. Historia de una pasión argentina. Prólogo de Marcos Aguinis, Buenos Aires: Corregidor, 1994 (1 ${ }^{\mathrm{a}}$ ed 1937).

Meyer, Doris. Victoria Ocampo. Against the Wind and the Tide. New York: George Braziller, 1979.

Ocampo, Victoria. De Francesca a Beatrice. Madrid: Revista de Occidente, 1924,

--.-. La laguna de los nenúfares. Madrid: Revista de Occidente, $\mathrm{T}$. XI, Madrid, 1926.

Supremacía del alma y de la sangre. Buenos Aires: Sur, 1935.

. La mujer y su expresión. Buenos Aires: Sur, 1936.

El viajero y una de sus sombras. Keyserling en mis memorias.

Buenos Aires: Sudamericana, 1951.

(1952): 166-169.

"Correspondencia: Carta a Ernesto Sábato". Sur 211-212

--_--, “Correspondencia: Sobre la metafísica del sexo”. Sur 213-214 (1952): 161-164.

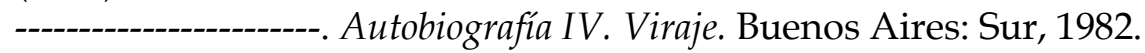

1983.

Autobiografía V. Versailles-Keyserling-Drieu. Buenos Aires: Sur, . Autobiografía VI. Sur y Cía. Buenos Aires: Sur, 1984.

Oliver, María Rosa. La vida cotidiana. Buenos Aires: Sudamericana, 1969.

Sábato, Ernesto. “Sobre la metafísica del sexo". Sur 209-210 (1952): 25-56.

"Correspondencia: Sobre la metafísica del sexo". Sur 213-214

(1952): 158-161.

VV.AA. “La mujer". Sur. Revista bianual 326-327-328 (1970-1971). 